\title{
Does the Fatigue Index Induced in Athlete's Affect Static Balance?
}

\author{
Recep Soslu ${ }^{1}$ \\ ${ }^{1}$ Physical Education and Sport, Karamanoğlu Mehmetbey University, Karaman, Turkey \\ Correspondence: Recep Soslu, Karamanoğlu Mehmetbey University, Physical Education and Sport, Karaman, \\ Turkey. E-mail: recepsosli@gmail.com
}

Received: July 25, 2019

Accepted: August 20, 2019 Online Published: September 19, 2019

doi:10.5539/jel.v8n5p81

URL: https://doi.org/10.5539/jel.v8n5p81

\begin{abstract}
Balance is the process of maintaining the body center of gravity vertically over the base of support and relies on rapid, continuous feedback and integration of afferent information coming from three sensory components, that is somatosensory, visual, and vestibular systems, resulting in smooth and coordinated neuromuscular actions. To investigate the effects of fatigue index on the static balance of sportsmen. A total of 51 male elite sportsmen from 4 different sports branches (Football players: 19, Volleyball players: 13, Skiers: 10 and Athletes: 9) participated in the study. The Wingate anaerobic power and capacity test was applied to induce fatigue. The Technobody isokinetic balance meter (Pro-Kin. CSMI) was used to measure pre- and post-fatigue static balance. There was a significant interaction between dependent (pre and post test balance) and independent (test statue and sport branches) variables were observed $\left.\left(\mathrm{F}_{663,1031.14}\right)=1.59, \eta^{2}=.07, \mathrm{p}<.05\right)$. Main effect results showed that pre-fatigue balance values were significantly different than post-fatigue balance values in all groups $(\mathrm{F}(1.14$, $\left.\left.{ }_{213.91}\right)=177.99, \eta^{2}=.49, \mathrm{p}<.05\right)$. Moreover, significant differences were identified between pre- and post-fatigue test results in sport branches $\left(F(3.188)=4.12, \eta^{2}=.06, \mathrm{p}<.05\right)$ and test statue (eyes open and closed) $(F(3.188)=$ $3.32, \mathrm{\eta}^{2}=.05, \mathrm{p}<.05$ ). Bonferonni follow-up test indicated that there was a significant increase from footballers' average static balance to the athletes' average static balance $(\mathrm{p}<.05)$. In test statue, pre fatigue eyes closed values were significantly different than post fatigue eyes opened values $(p<.05)$. Static balance training should be included in the training to be performed, fatigue static balance training should be performed in team and individual sports and the content of the training should be reorganized in line with the results obtained.
\end{abstract}

Keywords: fatigue index, static balance

\section{Introduction}

The majority of research in the field of movement and training science is concerned with sportive performance and the factors affecting it (Kılınç, Günay, Kaplan, \& Bayrakdar, 2018). Balance, which is at the center of sportive performance and conditional playsimportant roles in successful performance of many sports skills and maintaining certain positions of the body (Erdoğan et al., 2017). Balance can be defined as the ability to the center of gravity onthe support base with minimum swing and maximum stability (Alcantara, Prado, \& Duarte, 2012). Young athletesmay show better improvement in balance and coordination skills than adult athletes, and thus, it is important to know which sport, activity, exercise and protocol are more effective in developing these skills at that age (Ricotti \& Ravaschio, 2011). Ithas been suggested that age/maturation may have an impact on the association of selected components of balance and lower-extremity muscle strength (Muehlbauer, Granacher, \& Gollhofer, 2015). It is a common view that balance ability is a different indicator of sportive performance in sports requiring static and dynamic performance, and different methods and protocols are used in evaluation of balance (Ateş, Çetin, \& Yarım, 2017). Static balance can be exlpained asan object remains in a certain position when the applied forces on the object are in the opposite directions from each other and equal in amount (Inal, 2013). Athletesengaging in football, volleyball, skiing and track and fieldtry to maintain their static balances with Hamstring muscles in their lower extremities. Hamstrings are two articulated muscles and are often exposed to longer term expressions, higher velocities and smaller forces (Sarabon, Rosker, Panjan, \& Fonda, 2013). There are mainly small-scale correlations between static balance and lower extremity muscle strength measurements. In other words, these neuromuscular components are independent ofeach other, yet they should be tested and trained complementarily (Alcantara, Prado, \& Duarte, 2012).

Lower extremity muscles fatigue affects the static balance performances of athletes (Navarro, Gullon, \& Conesa, 2015). Fatigue index is stated as the percentage of reduction in power that takes place during the lower extremity 
tests (Özkan, Köklü, \& Ersöz, 2010). The lower extremity muscle resistance training, improves thecenter of pressure and static balance and reduces the risk of fall (Rafati, Eslami, \& Mirdar, 2018). The single leg stance may not accurately suggest an athlete'sankle instability and its function on physical activity, and it affects static balance (Toyookaa et al., 2018). Another factor affecting static balance is the visual and audio cues. The nature of sport in which one engages in and the lack of visual control are some of the significant determinants of static balance in elite athletes (Hammami et al., 2014). Therefore, during measurements of the static balance, both eyes open and closed conditions should be tested (Clark, \& Watkins, 1994). Trainers are recommended touse exercises performed with eyes open and closed on challenging surfaces to improve static balance in terms of training and evaluation (Hammami et al., 2014). In addition to a comprehensive neuromuscular training program including components of strength and resistance training, static balance trainings maylead to simultaneous performance gains as well as reducingthe risk of injury (Chander \& Dabbs, 2016).

Studies in the field of sports science investigated static and dynamic balance conditions of athletes with regard to physical fitness parameters. To our knowledge, there is no study in the relevant literature reporting how fatigue index affects static balance. In this respect, our study can be a pioneer in the literature. The aim of this study was to determine and assess the effects of fatigue index on static balance of elite athletes engaging in several sports.

\section{Method}

\subsection{Sample and Procedure}

51 male athletes engaging in elite sports voluntarily participated in the study. Distribution of the participants were as follows: (Football Players: 19, Volleyball players: 13, Skiers: 10 and Athletes: 9). The content of the study was explained in detail to all sportsmen who would participate in the study and they were warned not to make heavy exercises one day before the measurements and not to consume alcohol. Subjects with lower and upper limb injuries, head injuries, vision problems and any other complaints that could have affected balance measurement were excluded. The study was carried out in one day. The height of the athletes who participated in the study was measured using Stadiometer, and body weight measurements were performed using Tanita (Bio İmpadans Analisys). During the measurement, participants were asked to take off their shoes, heavy clothing, hats and berets. Body weights measured were recorded in ' $\mathrm{kg}$ '. The height of a participant was measured when the participant stood with their back facing the height meter, back of head, back and buttocks touching Stadiometer and feet close together. The participant was asked to look straight ahead and the sliding bar of the Stadiometer was lowered and flatly pressed against the hair of the participant. Measurements taken were recorded in 'cm'.

\subsection{Measures}

\section{Anaerobic Measurements:}

Wingate anaerobic power and capacity test (Want) was used to create fatigue index in lower extremities of the participants. The sitting level was adjusted while the participant was in the sitting position on the seat, pedaling, so that the knee would be at full extension when the pedal was at the lowest point, and the feet were fixed to the pedal with the help of clips. For each participant, the test was carried out after various loads were placed in the cage of the bicycle ergometer as external resistance to be applied during the test. The participants were asked to reach the highest pedal speed as soon as possible without resistance. When the pedal speed reached 150 cycles/min, the load automatically came down and the test was started. The participants pedaled at the highest speed for 30 seconds against resistance. The same protocol was applied to all participants (Özkan, Köklü, \& Ersöz, 2010).

\section{Static Balance Measurements:}

The static balance of the participants was measured using the Tecnobody isokinetic balance meter (Pro-Kin. CSMI). This instrument provides objective measurable data during balance measurements. The movable balance platform of the system working with air piston servo motors can measure in every direction with an operating angle of 15 degrees. The results can be viewed and recorded live on the screen on the device. The static balance test was conducted twice, being before and after the Wingate test (after the fatigue index is formed). After the test was explained to the participants, the data of the participants were entered into the computer (height, weight, age) and the device was calibrated. Before the first measurement, warming up process, including 5 minutes of low-tempo running, calisthetic movements, opening-stretching exercises, was completed in 10 minutes. After 2 minutes of exercise on the balance platform, the participants were tested with the body sensor connected to the chest. The test was conducted in two-legged stance with eyes open and in two-legged stance with eyes closed. During measurement in two-legged stance, feet shoulder-width apart, the stance positions of the feet were at 
equal distance from the origin point based on the lines on $\mathrm{X}$ and $\mathrm{Y}$ axes. During the test, participants were asked not to receive any support from their arms. The purpose of this stance was to decrease the effect of arms on balance and the chance to mislead the test by the person contacting the support rail. If the participant did not maintain their balance during the measurement period or it was observed that they have touched the tool with their hands or feet, the measurement was canceled and the test was repeated. After the test was started, 1 min breaks were given between the test series. During the test which lasted for 30 seconds in total, the participant was asked to keep their position and allowed to follow their position on the screen. After each test was completed, the device was recalibrated. The data and units generated as a result of the static balance test are as follows (Soslu et al., 2018).

Static balance values:
1) Average Pressure Centre X, mm (Average. C.O.P.X.)
2) Average Pressure Centre Y, mm (Average. C.O.P.Y.)
3) Forward- Backward Sway standard deviation, $\mathrm{sd} / \pm . \mathrm{mm}$
4) Medium-Lateral Sway standard deviation, $\mathrm{sd} / \pm . \mathrm{mm}$
5) Average Forward-backward speed, $\mathrm{mm} / \mathrm{s}$
6) Average Medium-Lateral speed, $\mathrm{mm} / \mathrm{s}$
7) Perimeter $\mathrm{mm}$
8) Ellipse Area $\mathrm{mm}^{2}$

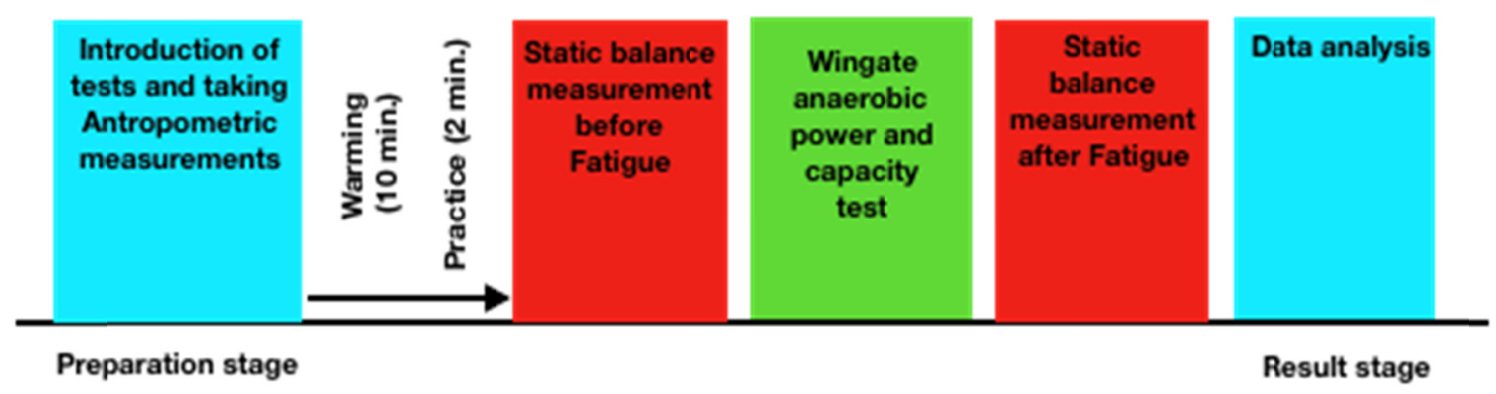

Figure 1. Experimental design

\subsection{Data Analyses}

The data obtained in this study were evaluated with the SPSS 23 package program. The pre- and post-fatigue distributions of the variables by groups were examined, the normality of the distributions and homogeneity of variances were done by Mauchly Sphericity and Levene test. The groups showed normal distribution and homogeneity of variance. Analysis of the effects of inter-group and intra-group and fatigue index was performed by Two-Way Manova in Repeated Measurements. Two-way Manova test was considered appropriate because there were more than two variables and repeated measurements. Post Hoc comparisons were determined by Bonferroni test in the case of significant values. Significance degree was accepted as 0.05 .

\section{Results}

As a result of the statistical analysis of the data obtained, pre-/post-fatigue, eyes open/ eyes closed balance and intergroup/ intragroup balance statuses are shown in Table 1, 2, 3, 4, 5 and 6. 
Table 1. Multivariate analyze results for all groups

\begin{tabular}{lllllll}
\hline & & $\boldsymbol{F}$ & Hypothesis $\boldsymbol{d} \boldsymbol{f}$ & Error $\boldsymbol{d} \boldsymbol{f}$ & Sig. & $\boldsymbol{\eta}^{\mathbf{2}}$ \\
\hline Balance & Pillai's Trace & 295.37 & 7.00 & 182.00 & .00 & .92 \\
& Wilks' Lambda & 295.37 & 7.00 & 182.00 & .00 & .92 \\
& Hotelling's Trace & 295.37 & 7.00 & 182.00 & .00 & .92 \\
Balance*Sport & Roy's Largest Root & 295.37 & 7.00 & 182.00 & .00 & .92 \\
Branches*Test Statue & Pillai's Trace & 1.55 & 63.00 & 1316.00 & .00 & .07 \\
& Wilks' Lambda & $\mathbf{1 . 5 9}$ & $\mathbf{6 3 . 0 0}$ & $\mathbf{1 0 3 1 . 1 4}$ & $\mathbf{. 0 0}$ & $\mathbf{. 0 7}$ \\
& Hotelling's Trace & 1.63 & 63.00 & 1262.00 & .00 & .08 \\
& Roy's Largest Root & 5.70 & 9.00 & 188.00 & .00 & .21 \\
\hline
\end{tabular}

MANOVA results indicated that significant interaction between dependent and independent variables were observed $\left.\left(\mathrm{F}_{63,1031.14}\right)=1.59, \eta^{2}=.07, \mathrm{p}<.05\right)$. Because interaction was observed, main effects of group results were checked.

Table 2. The results of pre and post- fatigue static balance within groups

\begin{tabular}{llllll}
\hline & & $\boldsymbol{d f}$ & $\boldsymbol{F}$ & $\boldsymbol{S i g .}$ & $\boldsymbol{\eta}^{\mathbf{2}}$ \\
\hline Balance & Sphericity Assumed & 7 & 177.99 & .00 & .49 \\
& Greenhouse-Geisser & $\mathbf{1 . 1 4}$ & $\mathbf{1 7 7 . 9 9}$ & $\mathbf{. 0 0}$ & $\mathbf{. 4 9}$ \\
& Huynh-Feldt & 1.23 & 177.99 & .00 & .49 \\
& Lower-bound & 1.00 & 177.99 & .00 & .49 \\
Error & Sphericity Assumed & 1316 & & & \\
& Greenhouse-Geisser & 213.91 & & & \\
& Huynh-Feldt & 231.52 & & & \\
& Lower-bound & 188.00 & & & \\
\hline
\end{tabular}

Table 2 shows that pre- and post-fatigue static balance values were significant in all groups $(\mathrm{F}(1.14,213.91)=$ $\left.177.99, \eta^{2}=.49, \mathrm{p}<.05\right)$.

Table 3. Intergroup pre-/post- fatigue static balance status

\begin{tabular}{lllll}
\hline & $\boldsymbol{d} \boldsymbol{f}$ & $\boldsymbol{F}$ & Sig. & $\boldsymbol{\eta}^{2}$ \\
\hline Sport Branches & 3 & 4.12 & .01 & .06 \\
Fatique & 3 & 3.32 & .02 & .05 \\
Error & 188 & & & \\
\hline
\end{tabular}

In consideration of Table 3, significant differences were identified between pre- and post-fatigue test results in sport branches $\left(F(3.188)=4.12, \mathrm{\eta}_{2}=.06, \mathrm{p}<.05\right)$ and fatique $\left(F(3.188)=3.32, \mathrm{\eta}_{2}=.05, \mathrm{p}<.05\right)$. Follow-up results of sport branches (see table 4 ) and fatique (Table 5) are explained below.

Table 4. Bonferonni follow-up test results of sport branches

\begin{tabular}{lllll}
\hline & Groups & Mean Difference & SD & Sig \\
\hline Football Players & Volleyball Players & 35.13 & 13.43 & .06 \\
& Skiers & 24.96 & 14.57 & .53 \\
& Athletes & $47.07^{*}$ & 15.09 & .01 \\
\hline
\end{tabular}

According to Table 4, a significant increase was established in the footballers' average static balance, compared to the athletes' average static balance $(\mathrm{p}<.05)$.No significant difference was found between the average static balance of footballers and that of volleyball players and skiers; between the average static balance of volleyball players and that of footballers, skiers and athletes, between the average static balance of skiers and that of footballers, volleyball players and athletes and between the average static balance of athletes and that of volleyball players and skiers $(\mathrm{p}>.05)$. 
Table 5. The results of static balance pre- and post- fatigue when eyes open and eyes closedstatuesall groups

\begin{tabular}{lllll}
\hline & & Mean Difference & S.E & Sig. \\
\hline Pre-fatigue eyes open & Pre-fatigue eyes open & 38.80 & 15.39 & .08 \\
& Post-fatigue eyes open & $43.83^{*}$ & 15.39 & .03 \\
& Post-fatigue eyes closed & 21.22 & 15.39 & 1.00 \\
\hline
\end{tabular}

Note. $* \mathrm{p}<.05$.

Table 5 showed that pre fatigue eyes closed values were significantly different than post fatigue eyes opened values $(p<.05)$. No significant difference was found among other groups $(p>.05)$.

Table 6. Static balance test results of the all gruops (Football Players, Volleyball Players, Athletes, Skiers)

\begin{tabular}{|c|c|c|c|c|c|c|c|c|c|}
\hline Variables & & C.o.P.X & C.o.P.Y & F.B.S.D & M.L.S.D & $\begin{array}{l}\text { A.F.B.S } \\
(\mathrm{mm} / \mathrm{sec} .)\end{array}$ & $\begin{array}{l}\text { A.M.L.S } \\
(\mathrm{mm} / \mathrm{sec} .)\end{array}$ & $\begin{array}{l}\text { Perimeter } \\
(\mathrm{mm})\end{array}$ & $\begin{array}{l}\text { EllipseArea } \\
\left(m m^{\wedge} 2\right)\end{array}$ \\
\hline Football & $X$ & $. \mathbf{5 0} \pm .06$ & $\mathbf{- 1 . 6 8} \pm .54$ & $4.68 \pm 2.11$ & $\mathbf{2 . 8 4} \pm .90$ & $\mathbf{1 0 . 6 3} \pm 2.69$ & $9.00 \pm 3.74$ & $\mathbf{4 0 3 . 7 9} \pm 27.26$ & $\mathbf{2 4 2 . 3 2} \pm 27.69$ \\
\hline \multirow[t]{3}{*}{ Players } & $y$ & $1.74 \pm 3.31^{*}$ & $-\mathbf{- 1 . 5 3} \pm .18^{*}$ & $\mathbf{5 . 3 7} \pm 2.48^{*}$ & $\mathbf{3 . 6 3} \pm 1.26^{*}$ & $16.42 \pm 4.30^{*}$ & $11.42 \pm 3.52^{*}$ & $\mathbf{5 4 0 . 6 3} \pm 24.45^{*}$ & 378.74 $\pm 74.91^{*}$ \\
\hline & $a$ & $. \mathbf{8 4} \pm .26$ & $\mathbf{- 3 . 0} \pm .34$ & $\mathbf{7 . 6 8} \pm .08$ & $\mathbf{4 . 7 4} \pm 2.96$ & $\mathbf{2 0 . 0 5} \pm 9.44$ & $12 \pm 5.74$ & $\mathbf{6 2 8 . 3 2} \pm 73.68$ & $\mathbf{8 0 5 . 0 5} \pm 84.03$ \\
\hline & $b$ & $4.84 \pm .92^{*}$ & $\mathbf{- 3 . 3 7} \pm .80^{*}$ & $\mathbf{5 . 6 3} \pm 1.71^{*}$ & $\mathbf{3 . 2 6} \pm 1.15^{*}$ & $\mathbf{2 0 . 0 5} \pm 6.01^{*}$ & $9.74 \pm 3.00^{*}$ & $\mathbf{5 8 3 . 7 9} \pm 63.05^{*}$ & $\mathbf{3 3 7 . 5 3} \pm 51.41^{*}$ \\
\hline Volleyball & $X$ & $. \mathbf{3 8} \pm .04$ & $\mathbf{- . 3 8} \pm .23$ & $\mathbf{3 . 8 5} \pm 1.31$ & $2.92 \pm 3.17$ & $\mathbf{9 . 8 5} \pm 4.86$ & $7.8 \pm 4.34$ & $\mathbf{3 5 0 . 6 2} \pm 59.49$ & $\mathbf{3 8 6 . 3 8} \pm 97.14$ \\
\hline \multirow[t]{3}{*}{ Players } & $y$ & $.69 \pm 0.7^{*}$ & $.08 \pm .50^{*}$ & $4.38 \pm 1.87^{*}$ & $2.15 \pm .55^{*}$ & $\mathbf{1 4 . 2 3} \pm 3.17^{*}$ & $7.38 \pm 1.94^{*}$ & $\mathbf{4 2 5 . 7} \pm 88.42^{*}$ & $163.85 \pm 62.70^{*}$ \\
\hline & $a$ & $\mathbf{- 2 . 1} \pm .05$ & $\mathbf{2 . 1 5} \pm .64$ & $\mathbf{6 . 6 2} \pm 2.06$ & $\mathbf{3 . 1 5} \pm 1.46$ & $\mathbf{1 2 . 8 5} \pm 4.95$ & $\mathbf{7 . 0 0} \pm 3.89$ & 394.6 \pm 55.89 & $\mathbf{3 2 4 . 5 4} \pm 64.92$ \\
\hline & $b$ & $. \mathbf{3 8} \pm .74^{*}$ & $1.38 \pm .90^{*}$ & $4.69 \pm 3.99^{*}$ & $\mathbf{3 . 0 8} \pm 1.55^{*}$ & $\mathbf{1 5 . 3 1} \pm 3.33^{*}$ & $8.00 \pm 4.62^{*}$ & $458.00 \pm 22.80^{*}$ & $321.69 \pm 94.72^{*}$ \\
\hline \multirow[t]{4}{*}{ Skiers } & $X$ & $.70 \pm .25$ & $\mathbf{- 3 . 5 0} \pm .40$ & $6.70 \pm 5.42$ & $2.90 \pm 1.66$ & $\mathbf{9 . 6 0} \pm 4.01$ & $7.60 \pm 2.01$ & $\mathbf{3 6 4 . 7 0} \pm 90.84$ & $\mathbf{3 7 5 . 6 0} \pm 98.03$ \\
\hline & $y$ & $.20 \pm .07^{*}$ & $1.20 \pm .47^{*}$ & $4.50 \pm 2.64^{*}$ & $4.70 \pm 3.23^{*}$ & $9.70 \pm 2.95^{*}$ & $\mathbf{7 . 8 0} \pm 2.49^{*}$ & $419.20 \pm 74.90^{*}$ & $198.60 \pm 66.55^{*}$ \\
\hline & $a$ & $. \mathbf{9 0} \pm .68$ & $\mathbf{- 3 . 8 0} \pm .60$ & $7.10 \pm 3.67$ & $4.10 \pm 2.28$ & $12.70 \pm 3.65$ & $\mathbf{9 . 5 0} \pm 4.14$ & $\mathbf{4 3 2 . 8 0} \pm 96.99$ & $\mathbf{5 5 9 . 9 0} \pm 61.65$ \\
\hline & $b$ & $.70 \pm .23^{*}$ & $3.80 \pm .59^{*}$ & $7.20 \pm 4.94^{*}$ & $\mathbf{3 . 9 0} \pm 1.73^{*}$ & $11.20 \pm 5.51^{*}$ & $7.70 \pm 3.47^{*}$ & $441.90 \pm 93.40^{*}$ & $356.70 \pm 34.2^{*}$ \\
\hline \multirow[t]{4}{*}{ Athletes } & $X$ & $1.11 \pm .69$ & $-1.22 \pm .03$ & $4.11 \pm 2.67$ & $\mathbf{2 . 6 7} \pm 1.73$ & $\mathbf{9 . 9} \pm 4.99$ & $7.11 \pm 2.85$ & $\mathbf{3 4 7 . 7 8} \pm 40.25$ & $\mathbf{2 2 8 . 4 4} \pm 33.51$ \\
\hline & $y$ & $1.22 \pm .86^{*}$ & $.67 \pm .73^{*}$ & $\mathbf{3 . 0 0} \pm 1.00^{*}$ & $1.56 \pm .53^{*}$ & $8.9 \pm 2.15^{*}$ & $5.22 \pm 1.30^{*}$ & $294.00 \pm 55^{*}$ & $100.67 \pm 44^{*}$ \\
\hline & $a$ & $-.44 \pm .98$ & $.11 \pm .58$ & $\mathbf{5 . 9} \pm 1.83$ & $\mathbf{3 . 1 1} \pm 1.27$ & $\mathbf{1 2 . 9} \pm 4.11$ & $\mathbf{8 . 1 1} \pm 4.46$ & $\mathbf{4 2 7 . 5 6} \pm 33.35$ & $333.89 \pm 81$ \\
\hline & $b$ & $1.33 \pm .54^{*}$ & $4.9 \pm .50^{*}$ & $6.7 \pm 4.36^{*}$ & $2.7 \pm 1.12^{*}$ & $12.22 \pm 4.27^{*}$ & $7.11 \pm 3.37^{*}$ & 390.44 $\pm 22.36^{*}$ & $327.22 \pm 25.28^{*}$ \\
\hline
\end{tabular}

Note. $*(\mathrm{p}<.05) \mathrm{x}$; pre fatique open eyes, $\mathrm{y}$; post fatique open eyes a; pre fatique closed eyes, b; post fatique open eyes.

Table 6 is examined; It was determined that there was a statistically significant difference between the eyes of the all gruops (Football players, Volleyball Players, Athletes, Skiers) in terms of their eye-open and closed values, both before and after fatigue. In addition, it was found that the static balances after the fatigue were further deteriorated.

\section{Discussion}

\subsection{Study Limitations and Implications for Future Assessment}

There are many methods to investigate static balance, yet it is hard to call one asthe most appropriate method (Oshima et al., 2018). In this study, we investigated the effects of fatigue index on static balance of athletes and reached the following findings. A significant difference was identified between intra-group pre- and post-fatigue static balance measurementsexcept Average medium-lateral speed. Athletes' pre and post-fatigue eyes closed static balance measurements were significantly better than their eyes open static balance measurements. When inter-group static balance values were compared, there were significant differences between the groups. Static balances ofathletes engaging in individual sports were significantly worse than those engaging in team sports. However, there was no significant difference between static balance of the skierswho engage in an individual sportand static balance of the volleyball playerswho engage in a team sport. Navarro et al. (2015) reported rapid and significant decreases in single-legstatic balances (eyes open all time) after Wingate test of wrestlers. Johnston et al. (1998)concluded that there were significant decreases in static balances after induction of lower extremity fatigue of the participants. A study of Emery et al. (2005) found that static balance measurements conducted with eyes closed were better than those conducted with eyes open. Alcantara, Prado, and Duarte (2012) reported that static balance measurements conducted with eyes closed showed a positive increase compared to static balance measurements conducted with eyes open. Herpin et al. (2010) suggested that fencers performed better at static balance conditions with eyes closed rather than their static balance measurements with eyes open. Stanek et al. (2015) concluded that vertical postural stability of students doing sports more actively was better than their static balance with eyes open. Michalskaa et al. (2018) reported that dancers showed similar changes 
in their patterns of static balances without visual information compared to those of non-dancers. In a study by Sofianidis et al. (2017), it was reported that there was a significant reduction in body sway amplitude during tandem stance with eyes closedin the elderly, and it was concluded that the center of pressure displacement during single-legstance decreased.

In a study by Kartal (2014), sway values of basketball and football players with eyes closed were better than their sway values with eyes open. Hammami et al. (2014) suggested that a rugby player, who engages in a team sport, has a better static balancecompared to sprinters and jumpers, who engage in an individual sport. Kartal (2014) reported that doubleleg static balance of tennis players, who engage in an individual sportwas better than that of athletes engaging in team sports. Agostini et al. (2018) concluded that the static balances of volleyball players are better than those of track and field athletes and that static balance conditions of volleyball players change regarding the positions they play. The findings of these studies are similar to the results of our study. Lin et al. (2009) did not identify any significant difference between eyes open and closed dominant and nondominant singlelegstatic balance measurements. Hatton et al. (2017) reported that there was no significant difference between eyes open and closed, injury foot and healthy foot measurements. Klavina et al. (2017) noted that static balance parameters of children with and without disability are better eyes open condition compared to eyes closedmeasurements. The findings of these studies are not in line with the results of our study.

Several studies reported positive effects of balance training on static and dynamic balance (Granacher, Mueulbauer, Doerflinger, \& Strohmeier, 2011; Yu \& Yang, 2012; Mettler et al., 2015; Çankaya et al., 2015; Baccouch, Rebai, \& Sahli, 2015; Zemkova et al., 2017; Hamed, Bohm, Mersmann, \& Arampatzis, 2017; Simpson et al., 2017). More specifically, static balance exercises are suggested as more effective in balance performance than dynamic balance exercises (Erdoğan et al., 2017). A previous study reported thatthere were correlationsbetween balance and lower extremity power following a balance training and such increase affected balance positively (Muehlbauer, Granacher, \& Gollhofer, 2015). If a decrease in balance is detected, a training program may be recommended to improve athletes' balance and reduce the risk of injury (Knight et al., 2016). A well-designed resistance training program is a vital component to improve lower-body strength and it is important to apply exhaustive exercises to lower extremities on certain days (Cooper, Dabbs, Davis, \& Sauls, 2018). Multiple exercises including dynamic/static, proactive and reactive types of balance should be used during balance training to target each balance dimensionindividually (Kiss, Schedler, \& Muehlbauer, 2018)

\subsection{Conclusion}

As a result; according to the findings of this study, athletes performed better at the measurements of static balance with eyes closed compared to eyes open condition. Moreover, fatiguenegatively affected athletes' static balance performances. Static balance conditions in individual and team sports vary according to the sport. Static balance exercises should be included in the training program, pre and post-fatigue static balance training and measurements should be performed in team and individual sports, and the training program should be reorganized in line with the results obtained.

\section{References}

Agostini, V., Chiaramello, E., Knaflitz, M., Canavese, L., \& Bredariol, C. (2018). Postural sway in volleyball Players. STAMPA, 32, 445-456.

Alcantara, C. P. A., Prado, J. M., \& Duarte, M. (2012). Analysis of the balance control in surfers during the erect posture. Locomotor Apparatus in Exercise and Sports, 18, 5.

Ateş, B., Çetin, E., \& Yarım, İ. (2017). Kadın sporcularda denge yeteneği ve denge antrenmanları. Gazi Üniversitesi Spor Bilimleri Dergisi, 2, 2.

Baccouch, R., Rebai, H., \& Sahli, S. (2015). Kung-fu versus swimming training and the effects on balance abilities in young adolescents. Physical Therapy in Sport, 16, 349-354. https://doi.org/10.1016/j.ptsp.2015.01.004

Cankaya, S., Gökmen, B., Taşmektepligil, M.Y., \& Con M. (2015). Special Balance developer training applicationson young males' static and dynamic balance performance. The Anthropologist, (19), 31-39. https://doi.org/10.1080/09720073.2015.11891636

Chander, H., \& Dabbs, N. C. (2016). Balance performance and training among female athletes. National Strength and Conditioning Association, 38, 2. https://doi.org/10.1519/SSC.0000000000000204

Clark, J. E., \& Watkins, D. L. (1984). Static balance in young children. Society for Research in Child Development, 55, 854-857. https://doi.org/10.1111/j.1467-8624.1984.tb03822.x 
Cooper, C. N., Dabbs, N. C., Davis, J., \& Sauls, N. M. (2018). Effects of lower body muscular fatıgue on vertıcal jump and balance performance. National Strength and Conditioning Association, 1-8. https://doi.org/10.1519/JSC.0000000000002882

Emery, C. A., Cassidy, J. D., Klassen, T. P., Rosychuk, R. J., \& Rowe, B. H. (2005). Development of a clinical static and dynamic standing balance measurement tool appropriate for use in adolescents. Physical Therapy, 85,6 .

Erdoğan, C. S., Er, F., Çolakoğlu, T., Zorba, E., Çolakoğlu, F. F. et al. (2017). Farklı denge egzersizlerinin voleybolcularda statik ve dinamik denge performansı üzerine etkileri. Spor ve Performans Araştırmaları Dergisi, 8,1 .

Granacher, U., Mueulbauer, T., Doerflinger, B., \& Strohmeier, R. (2011). Promotıng strength and balance in adolescents durıng physical education: effects of a short-term resistance training. Journal of Strength and Conditioning Research, 25, 940-949. https://doi.org/10.1519/JSC.0b013e3181c7bb1e

Hamed, A., Bohm S., Mersmann, F., \& Arampatzis, A. (2017). Exercises of dynamic stability under unstable conditions increase muscle strength and balance ability in the elderly. Scand J Med Sci Sports, 28, 961-971. https://doi.org/10.1111/sms.13019

Hammami, R., Othman, A. B., Chtara, M., Chaouachi, A., \& Behm, D. G. (2014). Comparison of static balance and the role of visionin elite athletes. Journal of Human Kinetics, 40, 33-41. https://doi.org/10.2478/hukin-2014-0030

Hatton, A. N., Crossley, K. M., Clark, R. S., Whitehead, T. S., Morris, H. G. et al. (2017). Between leg differences in challenging single limb balance performance one year following anterior cruciate ligament reconstruction. Gait \& Posture, 52, 22-25. https://doi.org/10.1016/j.gaitpost.2016.11.013

Herpin, G., Collet, P., Gauchard, G. C., Lion, A., Keller, D. et al. (2010). Sensorimotor specificities in balance control of expert fencers and pistol shooters. Journal of Electromyography and Kinesiology, 20, 162-169. https://doi.org/10.1016/j.jelekin.2009.01.003

İnal, H. S. (2013). Spor ve Egzersizde. Vücut Biyomekaniği, 2, 43-45.

Johnston, R. B., Howard, M. E., Cawley, P. W., \& Losse, G. M. (1998). Effect of lower extremity muscular fatigue on motor conrtol performance. Medicine \& Science in Sports \& Exercise, 30, 1703-1707. https://doi.org/10.1097/00005768-199812000-00008

Kartal A. (2014). Comparison of static balance in different athletes. Anthropologist, 18, 811-815. https://doi.org/10.1080/09720073.2014.11891613

Kılınç, H., Günay, M., Kaplan, Ş., \& Bayrakdar, A. (2018). 7-12 yaş arası çocuklarda yüzme egzersizi ve thera-band çalışmalarının dinamik ve statik dengeye etkisinin incelenmesi. Journal of Human Sciences, 15, 3. https://doi.org/10.14687/jhs.v15i3.5299

Kiss, R., Schedler, S., \& Muehlbauer, T. (2018). Associations between types of balance performance in healthy individuals across the lifespan: a systematic review and meta-analysis. Frontiers in Physiology, 9, 1366. https://doi.org/10.3389/fphys.2018.01366

Klavina, A., Rodke, A. Z., \& Galeja, Z. (2017). The assessment of static balance in children with hearing visual and intellectual disabilities. Acta Gymnica, 47, 105-111. https://doi.org/10.5507/ag.2017.013

Knight, A. C., Holmes, M. E., Chander, H., Kimble, A., \& Stewart, J. T. (2016). Assessment of balance among adolescent track and field athletes. Sports Biomechanics, 15, 169-179. https://doi.org/10.1080/14763141.2016.1159324

Lin, W. S., Liu, Y. F., Hsieh, C. C. H., \& Lee, A. J. Y. (2009). Ankle eversion to inversion strength ratio and static balance control in the dominant and nondominant limbs of young adults. Journal of Science and Medicine in Sport, 12, 42-49. https://doi.org/10.1016/j.jsams.2007.10.001

Mettler, A., Chinn, L., Saliba, S. A., Mckeon, P. O., \& Hertel, J. (2015). Balance training and center-of-pressure locationin participants with chronic ankle instability. Journal of Athletic Training, 50, 343-349. https://doi.org/10.4085/1062-6050-49.3.94

Michalska, J., Kamieniarz, A., Fredyk, A., Bacik, B., Juras, G. et al. (2018). Effect of expertise in ballet dance on static and functional balance. Gait \& Posture, 64, 68-74. https://doi.org/10.1016/j.gaitpost.2018.05.034

Muehlbauer, T., Granacher, U., \& Gollhofer, A. (2015). Associations Between measures of balance and lower 
extremity muscle strength/power in healthy individuals acrossthe lifespan: a systematic review and meta-analysis. Sports Med, 45, 1671-1692. https://doi.org/10.1007/s40279-015-0390-z

Navarro, R. M., Gullon, J. M. L., \& Conesa, A. M. (2015). Can Balance skills predict olympic wrestling performance? Journal of Sport and Health Research, 7, 19-30.

Oshima, T., Nakase, J., Kitaoka, K., Shima, Y., Numata, H. et al. (2018). Poor static balance is a risk factor for non contact anterior cruciate ligament injury. Arthroscopy And Sports Medicine, 1-6. https://doi.org/10.1007/s00402-018-2984-z

Özkan, A., Köklü, Y., \& Ersöz, G. (2010). Wingate anaerobik güç testi. Uluslar arası İnsan Bilimleri Dergisi, 7 , 211.

Rafati, A. G., Eslami, M., \& Mirdar, S. (2018). The Effect of a Nine-weeks training program on the center of pressure indicators with open and closed eyes condition in the elderly male. Rehabilitation, 19, 1. https://doi.org/10.21859/jrehab.19.1.44

Ricotti, L., \& Ravaschio, A. (2011). Break dance significantly increases static balance in 9 years old Soccer players. Gait \& Posture, 33, 462-465. https://doi.org/10.1016/j.gaitpost.2010.12.026

Sarabon, N., Rosker, J., Panjan, A., \& Fonda B. (2013). Functional and neuromuscular changes in the hamstrings after drop jumps and leg curls. Journal of Sports Science and Medicine, 12, 431-438.

Simpson, J. D., Brandon, M. L., Eric, K. O., Chander, H., \& Knight, A. C. (2017). External load training does not alter balance performance in well-trained women. Sports Biomechanics, 17, 336-349. https://doi.org/10.1080/14763141.2017.1341546

Sofianidis, G., Dimitriou, A. M., \& Hatzitaki, V. (2017). A Comparative study of the effects of pilates and latin dance on static and dynamic balance in older adults. Journal of Aging and Physical Activity, 25, 412-419. https://doi.org/10.1123/japa.2016-0164

Soslu, R., Güler, M., Özer, Ö., Devrilmez, M., Cincioğlu, G. et al. (2018). Boksörlerde akut yorgunluğun static dengeye etkisi. Sportıve Spor Ĕ̈itim ve Rekreasyon Dergisi, 1, 19-30.

Stanek, E., Aleksandra, T., Justyna, D. B., \& Tarnowski, A. (2015). Postural balance assessment in children aged 7 to 9 years.as related to body weight.height.and physical activity. Biomedical Human Kinetics, 7, 135-141. https://doi.org/10.1515/bhk-2015-0020

Toyookaa, T., Urabe, Y., Sugiura, S., Takata, A., Shinozaki, M. et al. (2018). Does the single limb stance reflect chronic ankle instability in an athlete? Gait \& Posture, 66, 242. https://doi.org/10.1016/j.gaitpost.2018.08.023

Yu, D. H, \& Yang, H. X. (2012). The effect of Tai Chi intervention on balance in older males. Journal of Sport and Health Science, 1, 57-60. https://doi.org/10.1016/j.jshs.2012.03.001

Zemkova, E., Kyselovičová, O., Jeleň, M., Kováčiková, Z., Ollé, G. et al. (2017). Unilateral stability and visual feedback body control improves after three-month resistance training in overweight individuals. Journal of Motor Behavior, 49, 398-406. https://doi.org/10.1080/00222895.2016.1219307

\section{Copyrights}

Copyright for this article is retained by the author, with first publication rights granted to the journal.

This is an open-access article distributed under the terms and conditions of the Creative Commons Attribution license (http://creativecommons.org/licenses/by/4.0/). 